\title{
Novel three-sinus enlargement technique for supravalvular aortic stenosis without aortic transection
}

\author{
Shinya Yokoyama*, Hisao Nagato, Yuichi Yoshida, Shigeo Nagasaka, Kozo Kaneda and Noboru Nishiwaki
}

\begin{abstract}
Background: Although repair of a supravalvular aortic stenosis (SVAS) can be performed with low mortality rates, surgery for the complex form of SVAS continues to be associated with a high incidence of residual stenosis.

Case presentation: The patient was referred to our hospital at 1 month of age and was diagnosed with aortic valve stenosis (AS) by using echocardiography. Cardiac catheterization revealed moderate AS, and subsequent left ventriculography revealed discrete stenosis of the sino-tubular junction and a narrowed proximal ascending aorta. We performed a reconstructive operation for such heart defects involving novel three-sinus and ascending aorta enlargement without aortic root transection in a 6-month-old boy.

Conclusion: Our novel three-sinus enlargement technique is suitable for treating each type of SVAS and is a useful method for a baby particularly less than $10 \mathrm{~kg}$ without disturbing the growth of the ascending aorta.
\end{abstract}

Keyword: Supravalvular aortic stenosis, Aortic valve stenosis, Three-sinus enlargement, Infant

\section{Background}

Although repair of a SVAS can be performed with low mortality rates, surgery for the complex form of SVAS, including repair of a diffuse narrow ascending aorta or single patch repair, continues to be associated with a high incidence of residual stenosis. Here, we report a case wherein successful novel three-sinus and ascending aorta enlargement was performed in an infant. The new procedure involves three-dimensional combination of three patches without aortic root transection.

\section{Case presentation}

The patient was a 6-month-old male infant (weight, $5.9 \mathrm{~kg}$ ) diagnosed with aortic valve stenosis by echocardiography. Cardiac catheterization revealed moderate aortic valve stenosis due to thickened tricuspid valve, with left ventricular pressure of 143/- $\mathrm{mmHg}$ (end-diastolic pressure $11 \mathrm{mmHg}$ ) and an ascending aortic pressure of $83 / 38 \mathrm{mmHg}$ (mean, $57 \mathrm{mmHg}$ ). Subsequent left ventriculography revealed discrete stenosis of the sino-

\footnotetext{
* Correspondence: Yocky2001@aol.com

Department of Cardiovascular Surgery, Kinki University School of Medicine Nara Hospital, 1248-1, Otoda-cho, Ikoma, Nara 630-0293, Japan
}

tubular junction and a narrowed proximal ascending aorta [Fig. 1].

The operation was performed at 6 months of age. After median sternotomy, a $30-\mathrm{mm}$ square piece of autologous pericardium was harvested and treated with $0.6 \%$ glutaraldehyde solution. Subsequent morphological inspection of the outer structure was performed, and features nearly identical to those at the preoperative diagnosis were noted. Cardiopulmonary bypass was established with ascending aortic and bicaval cannulations, aortic cross clamping was performed and cardiac arrest was achieved with cold crystalloid cardioplegia.

First, an oblique incision was made on the anterior wall of ascending aorta. The proximal end of the incision was at the center of the non-coronary sinus. The second incision began within the lower third of the first incision line and was placed $2-3 \mathrm{~mm}$ to right of the left coronary artery orifice. Because the left main trunk originated from the center of the left sinus and turned to the left, this incision avoided damage to the left coronary artery orifice. This incision and patch closure resembles the Manouguian root enlargement. Then the third aortic incision began within the upper third of the first incision line and was placed $2-3 \mathrm{~mm}$ to the left of the right 


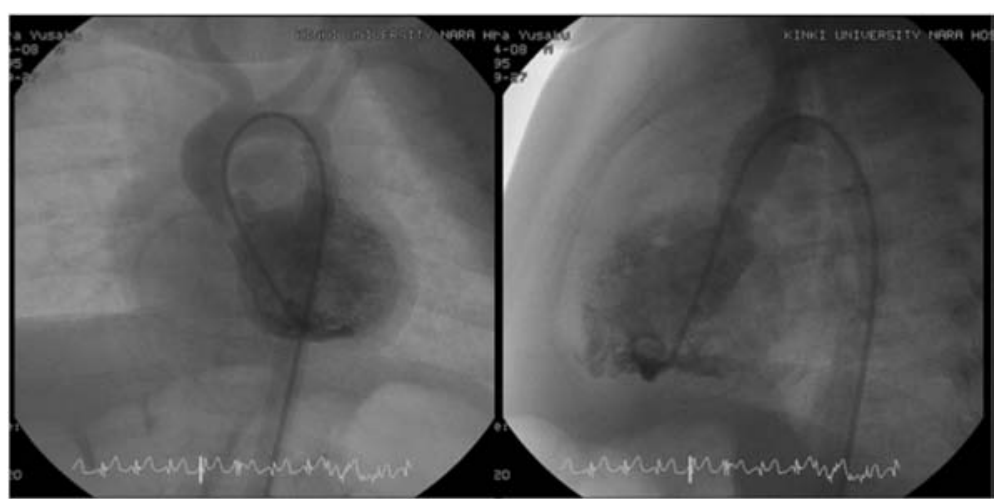

Fig. 1 Preoperative left ventriculography showed discrete stenosis of the sino-tubular junction and a narrowed proximal ascending aorta

coronary artery orifice. Because the right coronary artery originated from the center of the right sinus and turned to the right, the third incision avoided damage to the right coronary artery orifice. This incision and patch closure resembles the Konno root enlargement. After aortic valvoplasty with three directional commissurotomy and leaflet slicing, ascending aortoplasty was performed using the novel three-sinus enlargement technique. The second and third incisions were enlarged using a trimmed half-ellipse composite patch, prepared using autologous pericardium treated with $0.6 \%$ glutaraldehyde solution and Dacron velour fabric. Finally, the initial aortic oblique incision was enlarged using a fontanel-shaped composite patch attached with a single running suture [Fig. 2]. Cardiac catheterization was performed at
13 months after the procedure, and no stenosis in the left ventricular outflow tract was observed. The pressure gradient across the aortic annulus was $10 \mathrm{mmHg}$ or less [Fig. 3].

\section{Discussion}

Although the surgical strategy for SVAS has been established, complications such as aortic valve stenosis, diffuse ascending aortic stenosis, aortic coarctation, and coronary ostial stenosis impact surgical outcome [1]. Maintaining of symmetrical proportions of the ascending aorta, sufficient aortic diameter, and no residual stenosis in the left ventricular outflow tract is crucial for successful SVAS restoration.

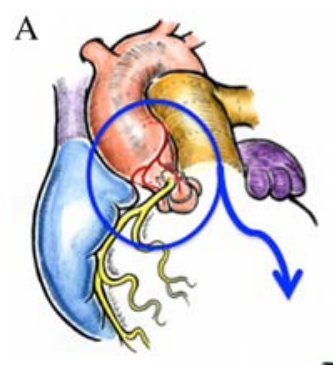

B

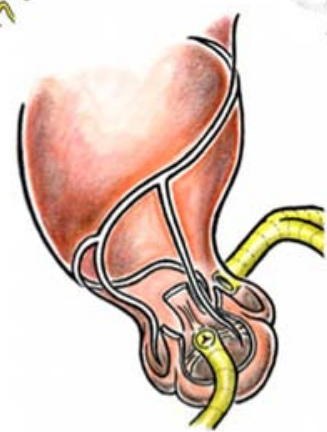

C
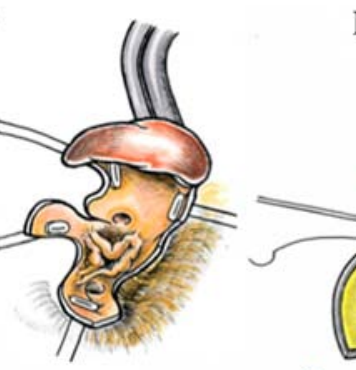

D

E

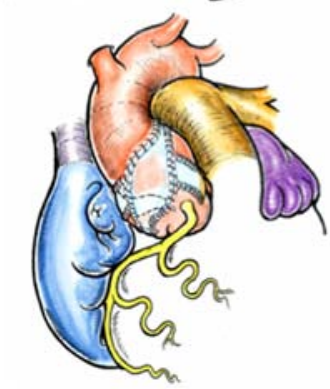

Fig. 2 Schematic diagram of the surgical technique: a The illustration shows the outer appearance before operation. $\mathbf{b}$ The incision line. c The ascending aorta is incised along the incision line. $\mathbf{d}$ The second and third incisions were enlarged using a trimmed ellipse patch respectively and the initial oblique incision was enlarged using fontanel shaped patch. e The illustration shows the outer appearance after operation 


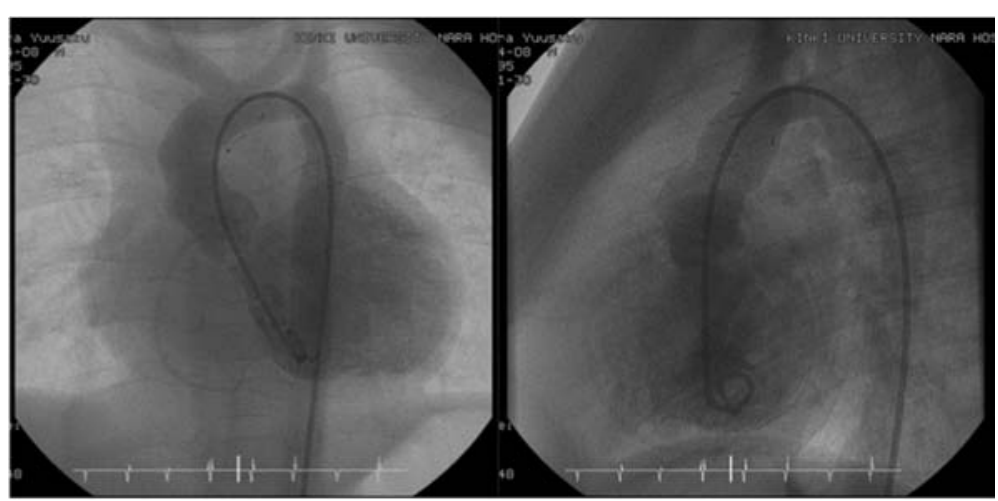

Fig. 3 Postoperative left ventriculography at 13 months after operation showed no stenosis in the ascending aorta and maintained of symmetry of the ascending aorta

Although the Myers method allows for repair without patches, diffuse types of SVAS are not effectively repaired by the method [2]. Single or two-sinus enlargements using one patch result in an asymmetrical aorta [3, 4]. Furthermore, the traditional three-sinus enlargements using multiple patches require aortic root transection [5]. Aortic root transection performed during infancy can cause aortic restenosis in the future. The operative technique had not been improved for a long time. We therefore developed a new method without aortic root transection to avoid aortic restenosis.

Here, we present a novel three-sinus enlargement technique that did not require aortic root transection. The chief advantage of this method is that the threesinus enlargement can be performed while maintaining an aortic continuity. This method is therefore believed to prevent residual aortic stenosis or future aortic restenosis owing to distortion of the reanastomotic suture line. In addition, the arrangement of the incisions is very important, and these incisions should be made with special care. If the incisions were made on the aortic wall near the coronary orifice, negative outcomes would result. Therefore, we referred to articles on aortic valve annulus enlargement techniques when creating the new arrangement of the incisions [6, 7].

The first oblique incision is an important element of the enlargement procedure for the narrow ascending aorta. The ascending aorta was incised in a spiral pattern, and patch enlargement of this incision allowed threedimensional enlargement of the narrow aorta without aortic root transection. To obtain sufficient enlargement after repairing a long narrow ascending aorta, conventional multiple patch methods required the use of some other patches [8]. However, the present method dose not requires additional patches to repair a long narrow ascending aorta and is therefore more effective for treating diffuse-type SVAS.

\section{Conclusions}

We report a successful novel three-sinus and ascending aorta enlargement without aortic root transection in a 6-month-old boy with SVAS and AS. Our novel threesinus enlargement technique is suitable for treating each type of SVAS and is a useful method for a baby particularly less than $10 \mathrm{~kg}$ without disturbing the growth of the ascending aorta.

\section{Consent}

Written informed consent was obtained from the patient for publication of this Case report and any accompanying images. A copy of written consent is available for review by the Editor-in-Chief of this journal.

\section{Abbreviations \\ SVAS: Supravalvular aortic stenosis; AS: Aortic valve stenosis.}

\section{Competing interests}

The authors declare that they have no competing interests.

Authors' contributions

$S Y, H N, Y Y, S N, K K$ and NN carried out the surgical procedure, participated in provision of clinical information and the manuscript. All authors read and approved the final manuscript.

\section{Acknowledgements}

We would like to thank F. Swezg, MD for providing the fine art work and figures.

Received: 27 July 2015 Accepted: 11 January 2016 RPl?

\section{References}

1. Stumm C, Kreutzer C, Zurakowski D, Nollert G, Friehs I, Mayer JE et al. Fortyone years of surgicall experience with congenitall supuravalvular aortic stenosis. J Thorac Cardiovasc Surg. 1999;118:874-85.

2. Myers JL, Waldhausen JA, Cyran SE, Gleason MM, Weber HS, Baylen BG. Results of surgicalrepair of congenital supravalvular aortic stenosis. J Thorac Cardiovasc Surg. 1993;105:281-7.

3. Mcgoon DC, Mankin HT, Vlad P, Kirklin JW. The surgicall treatment of supuravalvular aortic stenosis. J Thorac Cardiovasc Surg. 1961;41:125-33. 
4. Doty DB, Polansky DB, Jenson CB. Supravalvular aortic stenosis - repair by extended aortoplasty. J Thorac Cardiovasc Surg. 1977;74:362-71.

5. Brom AG. Obstruction of the left ventricular outflow tract. In: Khonsari S, editor. Cardiac surgert: safeguards and pitfalls in operative technique. 1st ed. Rockvill, MD: Aspen Publishers; 1988. p. 276-80.

6. Konno S, Imai $Y$, lida $Y$, Nakajima M, Tatsuno K. A new method for prosthetic valve replacement in congenital aortic stenosis associated with hypoplasia of the aortic valve ring. J Thorc Cardiovasc Surg. 1975;70:909-17.

7. Manouguian S, Seybold-Epting W. Patch enlargement of the aortic valve ring by extending the aortic incision into the anterior mitral leaflet. New operation technique. J Thoracic Cardiovasc Surg. 1979;78:402-12.

8. Arnáiz E, Koolbergen D, Adsuar A, Hazekamp MG. Surgery for supravalvular aortic stenosis-the three-patch technique. Multimedia Manual of CardioThoracic Surgery, 2008(0915), mmcts-2006.

Submit your next manuscript to BioMed Central and we will help you at every step:

- We accept pre-submission inquiries

- Our selector tool helps you to find the most relevant journal

- We provide round the clock customer support

- Convenient online submission

- Thorough peer review

- Inclusion in PubMed and all major indexing services

- Maximum visibility for your research

Submit your manuscript at www.biomedcentral.com/submit
Biomed Central 